\title{
Avaliação Formativa no Ensino Fundamental II: possibilidades da atuação docente
}

\author{
RAQUEL CALIL RUY \\ Colégio Marista de Londrina \\ rruy@marista.org.br \\ NADIA APARECIDA DE SOUZA \\ Professora da Universidade Estadual de Londrina - UEL \\ nadia@uel.br
}

\begin{abstract}
Resumo
A avaliação formativa pressupõe a utilização de informações coletadas pelos professores para regular as aprendizagens em curso. Ela traz, portanto, em seu bojo a compreensão do valor pedagógico do erro. O objetivo deste estudo foi compreender como vem sendo desenvolvida a avaliação formativa, referenciando-se na abordagem do erro e na conseqüente regulação das aprendizagens. Para o desenvolvimento dessa pesquisa elegeuse a ABORDAGEM QUALITATIVA, na modalidade ESTUDO DE CASO ETNOGRÁFICO. A averiguação foi realizada em uma escola da rede particular de ensino, em bairro próximo à região central de Londrina, Paraná. Participaram da investigação cinco professores que atuam nas áreas de Ciências, Geografia e História, do Ensino Fundamental II. Para a realização desta pesquisa foram efetivados: observação participante, entrevista semi-estruturada, além do estudo aprofundado do referencial teórico e documental. As informações obtidas foram agrupadas por unidades de significação e orientaram o delineamento das categorias de análise. $\mathrm{O}$ estudo dos dados revelou que os professores vêm implementando práticas avaliativas formativas, porque compromissadas com a progressão do aluno no sentido do domínio das aprendizagens em curso. O erro, portanto, assume função pedagógica, balizando e orientando o trabalho docente, ao sinalizar para as inconcretudes e inacabamentos ainda presentes no processo de aprendizagem.

Palavras-chave: avaliação da aprendizagem, erro construtivo, formação docente.
\end{abstract}

\section{Resumen}

La evaluación formativa presupone la utilización de informaciones recogidas por los profesores para regular los aprendizajes en curso. Por eso, ella trae en su cerne, la comprensión del valor pedagógico del error. El objetivo de este estudio fue comprender como está siendo desenvuelta la evaluación formativa, teniendo como punto de referencia el abordaje del error y la consecuente regulación de los aprendizajes. Para el desarrollo de esta investigación se escogió el ABORDAGE CUALITATIVO, en la modalidad ESTUDIO DE CASO ETNOGRÁFICO. La averiguación se hizo en una escuela de la red particular de enseñanza, en un barrio próximo a la región central de Londrina, Paraná. Participaron de la investigación cinco profesores que actúan en las áreas de Ciencias y Geografía e Historia de la Enseñanza Fundamental II. Para la realización de esta investigación fueron utilizados: observación 
participante y entrevista semi-estructurada, además del estudio profundizado del referencial teórico y documental. Las informaciones obtenidas se agruparon por unidades de significación y orientaron el delineamiento de las categorías de análisis. El estudio de los datos reveló que los profesores vienen adoptando prácticas de evaluación formativas, porque están comprometidas con la progresión del alumno en el sentido del dominio de los aprendizajes en curso. El error, por lo tanto, asume función pedagógica, balizando y orientando el trabajo docente, al señalar las inconcretizaciones y los inacabados que aún están presentes en el proceso de aprendizaje.

Palabras-clave: evaluación del aprendizaje, error constructivo, formación docente.

\begin{abstract}
Formative assessment assumes using information collected by teachers to regulate current learning. Therefore, it brings along an understanding of an error's teaching value. This paper aims at examining how formative assessment is being developed; this examination is based on an error approach and its consequent learning regulations. An ETHNOGRAPHIC CASE STUDY within a QUALITATIVE APPROACH gears this research. The data was collected in a school in a neighborhood close to downtown Londrina, in the state of Paraná. Five teachers of Sciences, Geography and History in Basic School II participated in the research. Participant observation and semi-structured interviews were used in addition to a thorough study of the theoretical and documental material. The information obtained was grouped by meaning units and guided the establishment of analysis categories. The study of the data revealed that the teachers have been adopting formative assessment practices because they are committed to the student's progress in current learning activities. Thus, error takes on a learning function, directing teacher's work by pointing out problematic and unfinished aspects still present in the learning process.
\end{abstract}

Key words: learning assessment, constructive error, teacher training. 


\section{DESCORTINANDO ASPIRAÇÕES E DESCREVENDO PERCURSOS}

A rapidez com que se dá a produção de novos conhecimentos em uma sociedade globalizada impõe importantes conseqüências sociais, econômicas e culturais. Entretanto, [...] apesar da sofisticação tecnológica, da complexidade do conhecimento, do alargamento das formas e processos de relação, na atualidade, o homem vivencia um tempo de crises e transformações (Souza, 2002, p.33).

Tais incertezas e instantâneas modificações balizam o pensar e o fazer do homem ao longo da vida, assim [...] essa verdadeira metamorfose atinge em cheio a escola que precisa, com urgência, atualizar seu projeto pedagógico, a fim de cumprir a finalidade de educar seus alunos para o exercício pleno da cidadania, bem como para a atuação no mercado de trabalho (Oliveira, Tescarolo, s.d.), que está exigindo novas competências, muito diferentes daquelas anteriormente reclamadas para a inserção no campo laboral.

No tracejar de seu percurso, a escola necessita [...] reformular o seu currículo, constituído pelo conjunto pedagogicamente selecionado e articulado das formas culturais e dos saberes historicamente construídos pela humanidade e a serem reconstruídos pelos alunos (Oliveira, Tescarolo, s.d.). Nos tempos atuais, o que é relevante para o educando não é simplesmente registrar, memorizar ou processar informações, mas é também e, principalmente, reestruturar um sistema de compreensão da realidade com intenção de transformá-la.

Com base nas considerações tecidas, pode-se inferir sobre a necessidade de modificações significativas na organização da sala de aula, na forma de olhar o aluno, na articulação entre ensino e aprendizagem e na superação dos pressupostos da avaliação, centrada apenas nos resultados e ligada às concepções de verticalidade e "meritocracia" do processo ensino/aprendizagem.

Pesquisadores em educação (Hadji, 2001a; Hoffmann, 2002; Luckesi, 2002; Perrenoud, 1999) vêm, ao longo do tempo, criticando a avaliação empreendida somente como instrumento de controle, punição e classificação, e defendendo a idéia de que seu conseguimento deve ser orientado para a coleta de dados que subsidiem e orientem as atividades de ensino a serem implementadas pelo professor, e atividades de aprendizagem a serem perseguidas pelos alunos.

A avaliação deve assumir, então, diversas funções, em decorrência de suas finalidades, dos elementos envolvidos em sua consecução ou da análise de seus resultados. Então, quer se processe de maneira individual ou coletiva, pelo professor ou pelo aluno, para auxiliar ou para classificar, a avaliação se apresenta, geralmente, como um conjunto de situações que se 
complementam para a obtenção de informações que pretendem contribuir para ajustar o gesto e, se preciso for, "corrigir o alvo", expressão comum que designa uma faculdade humana universal: a arte de conduzir a ação pelo olhar, em função de seus resultados provisórios e dos obstáculos encontrados (Perrenoud, 1999, p. 14-15).

Todavia, os educadores revelam, em diferentes momentos e em variadas circunstâncias que, para eles, faz-se muito presente $o$ entendimento da avaliação como um ritual, como um momento de testar as aprendizagens apenas para atribuir uma nota ou um conceito - enfim, um escore que traduza o saber evidenciado pelo aluno -, bem como implementar mecanismos de controle de conduta, sem aterem-se ao nãoapropriado visando a intervenções pedagógicas pertinentes e oportunas, até porque [...] os professores foram preparados - pelas instituições de ensino que freqüentaram, pelas muitas experiências que vivenciaram enquanto alunos $e$ enquanto educadores - para a subserviência, para a reprodução da ordem social vigente, para a imutabilidade das coisas (Souza, 2002, p. 34).

A avaliação encerra uma função relevante - colocar-se a serviço das aprendizagens o máximo possível (Hadji, 2001a, p. 15) - o que, em face do atual cenário, suscita algumas questões: como o professor vem exercitando uma avaliação que afirma ser formativa? Qual a compreensão de erro evidenciada no discurso e na prática docentes? Qual o espaço para a regulação das aprendizagens em decorrência das dificuldades de aprendizagem identificadas?

Elucidar tais questões exigiu, enquanto objetivo maior: compreender como vem sendo desenvolvida a avaliação formativa, tendo por referência a abordagem de erro evidenciada e a conseqüente regulação das aprendizagens em curso no sentido dos domínios visados, em um currículo voltado à formação integral dos alunos que cursam o Ensino Fundamental II ( $5^{a}$ a $8^{a}$ série).

Para atingir tal objetivo tornou-se necessário vivenciar o cotidiano dessa instituição de ensino, para: (a) observar no espaço da sala de aula as interações entre os sujeitos que ali se encontram, identificando e descrevendo as concepções avaliativas manifestas; (b) identificar e descrever as práticas avaliativas ocorridas em sala de aula e a abordagem pedagógica do erro; e (c) analisar as regulações promovidas pelos docentes em decorrência dos indicadores de não-aprendizagem evidenciados pelos dados coletados nas práticas avaliativas.

Para o desenvolvimento dessa pesquisa elegeu-se a ABORDAGEM QUALITATIVA, na modalidade ESTUDO DE CASO ETNOGRÁFICO, visto que o foco de estudo incide sobre o processo avaliativo, no modo como ocorre e na leitura e interpretação que os sujeitos envolvidos dão a ele. A pesquisa foi realizada em uma escola da rede particular de ensino, em um bairro 
próximo à região central de Londrina, no Estado do Paraná, que trabalha com os segmentos: Educação Infantil, Ensino Fundamental I ( $1^{\mathrm{a}}$ a $4^{\mathrm{a}}$ série), Ensino Fundamental II ( $5^{\mathrm{a}}$ a $8^{\mathrm{a}}$ série) e Ensino Médio. Apresentando uma proposta pedagógica diferenciada, orientada para a formação integral do aluno pela harmonização entre fé, cultura e vida, uma vez que considera o homem um ser livre, autor do seu desenvolvimento e da sua história.

Participaram da pesquisa cinco professores que atuam nas áreas de Ciências, Geografia e História, do Ensino Fundamental II. Eles foram selecionados, em razão do envolvimento que sempre tiveram com as questões do cotidiano escolar, por oferecerem um espaço para que as observações se efetivassem e por terem tempo para refletir e responder às questões da entrevista.

Para a realização desta pesquisa foram privilegiados variados procedimentos investigativos: observação, questionário, entrevista semiestruturada, além do estudo aprofundado do referencial teórico e documental. As informações obtidas foram agrupadas por unidades de significação - em virtude da freqüência com que se manifestaram no discurso e nas práticas - e orientaram o delineamento das categorias de análise. Uma das categorias analisadas foi a dimensão do erro na avaliação formativa.

\section{A DIMENSÃO DO ERRO NA AVALIAÇÃO FORMATIVA}

A combinação entre erro e fracasso está muito próxima; é como se um fosse conseqüência do outro ou, ainda, apresenta-se como uma lógica tão natural entre sucesso e fracasso que nem há necessidade de se ponderar sobre. Entretanto, para Carvalho $(1997$, p. 11) não são poucos os pensadores para quem o erro se associa a outras noções como esperança, conhecimento $e$ aprendizagem. Não são necessariamente pedagogos modernos, professores permissivos, nem reformadores educacionais.

Diferentemente, nas concepções tradicionais, o erro servia apenas como indicador do fracasso do aluno, e, também, segundo autores como Libâneo (1983), Rabelo (1995), Saviani (2002) - dentre outros -, para a sustentação do Estado, articulador de políticas capitalistas nas sociedades, por meio das mais diversas formas de exercício do poder.

O resultado deste método de classificação dos indivíduos é convencer a alguns de que são capazes, bons e desejáveis do ponto de vista do sistema, e a outros de que são deficientes, ruins e indesejáveis. É improvável que esta contínua rotulação traga conseqüências benéficas para o desenvolvimento educacional do indivíduo, e é muito provável que em muitos dos alunos exerça uma influência desfavorável sobre 
seu autoconceito. O fato de se permanecer aprisionado fisicamente (e legalmente) a um sistema escolar durante 10 a 12 anos e receber repetidamente classificações negativas durante este período deve exercer algum efeito prejudicial decisivo no desenvolvimento da personalidade e do caráter. (Bloom, Hastings, Madaus, 1983, p. 8)

Para Foucault (2005), o Estado, por si só, não conseguiria sustentar o poder, pois há uma rede de poderes, constituída de micropoderes que se fazem presentes nas práticas e relações humanas de qualquer tipo de sociedade. Apesar da conotação negativa geralmente conferida ao poder, o autor ressalta que alguns de seus aspectos são altamente positivos e construtivos, e considera que é necessário parar de descrever apenas os efeitos contraproducentes do poder.

A escola é um espaço no qual, também, as relações de micropoderes se manifestam. Se a face positiva, assim como a face negativa do poder podem revelar seus préstimos, é importante buscar alternativas para a promoção do crescimento e do aperfeiçoamento das pessoas e das situações vivenciadas.

Entretanto, não é isso o que acontece, pois o sistema escolar faz uso de um mecanismo sutil, mas decisivo, para reprimir, recalcar e, sobretudo, culpabilizar e justificar o cerceamento de oportunidades de muitos, enquanto favorece alguns. $\mathrm{O}$ mecanismo perspicaz e eficiente para perpetuar o domínio é o uso do erro como legitimador do fracasso da maioria e do sucesso de poucos.

O erro, utilizado para evidenciar o insucesso, a falta, a carência, a incapacidade; para justificar a repreensão, a censura, o cerceamento de oportunidades assume a função de disciplinamento dos indivíduos para que melhor se ajustem às expectativas sociais.

Portanto, re-significar o erro, re-significar o olhar que sobre ele se lança, é uma necessidade no exercício de uma prática avaliativa que pretende superar a perspectiva meramente classificatória para comprometer-se com a evolução e com a aprendizagem contínua do aluno.

Analisando o erro como indicador diagnóstico que fornece informações sobre as formas de constituição de relações entre os conhecimentos, os professores principiam na superação de um modelo em que o julgamento de um saber se fazia único, absoluto, classificatório, comparativo e competitivo, avançando na construção de uma percepção segundo a qual o acompanhamento dos processos de aprendizagem prioriza a cooperação, a participação, a inclusão e a vivência ética. 
O Professor A, conforme permite depreender a sua prática, compreende o erro como elemento que evidencia as dificuldades de aprendizagem e, portanto, enquanto sinalizador do espaço e do tempo para sua intervenção.

Para introduzir o conteúdo de solo e rochas, o professor, sabendo que essa matéria também era trabalhada por outros componentes curriculares, bem como em séries anteriores, fez um primeiro levantamento do conhecimento prévio dos alunos. Isso foi feito de forma oral. O professor lançava perguntas e os alunos iam respondendo naturalmente. $\mathrm{O}$ docente direcionou suas questões para as características do solo do norte do Paraná (nosso solo). Observou, então, que os alunos já possuíam bons conhecimentos sobre o assunto e sobre o fato de que somos "pés vermelhos" justamente por causa da nossa terra que é chamada roxa, pois rosso em italiano é vermelho. Demonstraram saber que os primeiros imigrantes a colonizarem nossas terras paranaenses foram os italianos. De posse dessas informações, o professor deu início ao conteúdo sobre a origem e os tipos de solo, bem como sobre rochas magmáticas (que são formadas pelo resfriamento do magma). O educador considerou que os alunos já tinham compreendido e dominavam os aspectos relativos à origem da "nossa terra vermelha" e prosseguiu com o conteúdo. Porém, durante uma atividade constituída de perguntas para serem respondidas sem consulta a nenhum material, nem aos colegas, uma das questões suscitou enorme dificuldade de resolução. Ela versava sobre a constituição do solo: "O basalto é um tipo de rocha que pode ser cinza-escuro ou castanho e aparece em vários lugares do sul do país. Assim, responda: $\mathrm{O}$ que a decomposição do basalto originou?" Exatamente nessa questão o professor observou que um número expressivo de alunos errou ou simplesmente deixou a resposta em branco. Percebeu, então, que havia algo de errado nas suas primeiras deduções sobre os conhecimentos prévios dos alunos acerca do tema. Decidiu levar esse resultado para ser discutido em sala de aula. Usou do seguinte procedimento: explicou para os alunos o que estava acontecendo, e juntos decidiram retomar todo o conteúdo desde o início.

1) Levantaram, juntos, o que entendiam por rochas magmáticas, e todos responderam: "São as rochas que se originam do resfriamento do magma" (e ainda explicaram que magma era a lava do vulcão).

2) Chegaram à conclusão, após algumas discussões, que precisariam saber a que tipo ou tipos de minerais elas deram origem. E, juntos, responderam: "ao granito e ao basalto". "Ótimo", diz o professor "e, agora, me digam: qual a cor do basalto?" Silêncio na sala; de repente levantam as mãos várias crianças e disseram: "professora, entendemos onde você quer chegar, pois se o basalto tem cor cinza-escuro, castanho é a sua decomposição, que originou a terra roxa e, conseqüentemente, isso aconteceu porque aqui existiram vulcões". "Isso mesmo!", vibra o professor. 
Um outro aluno levanta a mão e diz: "era exatamente isso que você perguntava na questão (a) da nossa última atividade". Mais feliz ainda, o professor responde: "É isso mesmo!!" "Todos entenderam agora?" "Pessoal, tem alguém que possui alguma dúvida sobre esse assunto?", pergunta o professor. E todos respondem que agora havia ficado mais claro do que antes esse assunto. (Professor A)

Ao valorizar as experiências trazidas pelos aprendentes, as partilhas, as assimilações e reflexões ativas do educando, as interações entre sujeito e objeto, e, uma vez que os educadores reconhecem a avaliação como mediadora da prática docente, o erro é redimensionado e passa da condição de determinante em classificar e separar os que aprendem dos que não aprendem, para ser parte do processo de construção de novos saberes.

Para La Taille (1997, p. 25), os estudos piagetianos redimensionaram o erro, de tal modo que,

De pecado capital da aprendizagem, o erro ganhou certa nobreza, foram demonstradas sua função e utilidade. [Ainda] em que pese a importância do erro nos processos de aprendizagem e desenvolvimento, tem-se a impressão de que algumas interpretações pedagógicas do construtivismo piagetiano "sacralizaram" o erro, tornando-o "intocável", e, por conseguinte, deram à sua prevenção (os modelos) e à sua correção - por parte do adulto, pai ou professor - um ar de profanação.

Valorizar o erro no transcurso do processo ensino/aprendizagem demanda bom senso e equilíbrio. Ele merece um olhar pedagógico marcado pela curiosidade compreensiva, pela inquirição reflexiva. Entretanto, ele não pode ser sacralizado e, portanto, inacessível a qualquer intervenção pedagógica.

Os professores investigados expuseram a definição de erro de maneira muito clara; entretanto, apenas quatro revelaram ter o seu significado e a sua função numa percepção bastante coerente com a perspectiva formativa, pois não consideraram o erro como condenação sumária e, também, entendem a importância de não aceitarem todo e qualquer erro como mais um momento de aprendizagem, relegando-o a uma simplificação permissiva.

Erro? Olha! ... Se a gente for analisar as questões referentes às visões de ensino/aprendizagem, desde 1990 até hoje, a gente percebe que não tem mais o erro na aprendizagem. Isso me preocupa muito, parece que tudo se relativizou. Olhando a partir das ciências de que "nada se perde, nada se cria, tudo se transforma", não existe erro, existem aproximações ou distâncias de um objetivo maior. Só que nós vivemos numa sociedade onde existem erros e acertos. As crianças, as famílias, a 
sociedade, a escola, a vida nos cobram o acerto. Assim, entendo que nós educadores temos a obrigação de levar o aluno a refletir sobre seu processo, sobre seus erros, seus acertos, suas escolhas e limitarmos o real do ideal para que o educando tenha parâmetros. Não consigo conceber a idéia de que nunca podemos "corrigir" o aluno e que ele por si só construirá sua aprendizagem. (Professor A)

É evidente, no relato do Professor A, que culpar e castigar seus alunos por errarem são dimensões já superadas, porém entende que os erros podem e devem constituir elementos norteadores das ações e intervenções pedagógicas. Compreende, também, que a reflexão acerca das hipóteses construídas pelo aluno faz com que as tarefas e atividades desenvolvidas sejam consideradas como elementos de investigação e não exclusivamente espaços de classificação.

O erro deve desencadear intervenção e/ou reflexão. Não basta corrigir e pontuar - como se fazia, e em muitas escolas ainda se faz - é necessário utilizar o erro para a re-organização do trabalho docente, na proposição de situações e tarefas diversas, bem como suscitar questionamentos que tornem o erro um observável para o aluno.

Erro...Erro... Em princípio é a falta de acerto. Procuro encarar o erro como algo natural. Nós, professores, muitas vezes, falamos do erro como falta de inteligência, o que não é verdade, ou usamos o erro para culpar o aluno, a família, a história de vida da criança, o contexto social em que essa criança está inserida, ou seja, o erro como legitimador do fracasso, o que também não é verdade. Eu venho de uma época em que o erro era percebido como estigmatizador dos bons alunos e dos "burrinhos". Dessa percepção saltamos para uma situação em que o professor que corrigisse um aluno era um carrasco, um louco; pôr certo ou errado de caneta vermelha era suficiente para condenar o professor à forca. Assim, busco usar o erro como instrumento de reflexão, tanto para mim, professor, quanto para o meu aluno, pois entendo o erro como uma parte de um edifício que ainda não foi construído e a aprendizagem como via de mão dupla. (Professor B)

O Professor B percebe o erro como parte do processo de aprendizagem e, retomando a história vivenciada, apresenta sua percepção: [...] o erro como instrumento de reflexão. Assim como para o Professor A, o erro é o momento da parada, é o instante da contemplação, no intuito de melhor compreender o que está acontecendo de fato. Mas a reflexão abarca professor e alunos, pois ambos são responsáveis pela superação das dificuldades.

Para o Professor B, professor e alunos, tendo as tarefas escolares como "desencadeadores" (Hadji, 2001b, p. 86), na produção de um resultado almejado, podem valer-se de seu produto para identificar conquistas e interpretar dificuldades. Desse modo, ao contrário de simplesmente analisar as atividades dos educandos, a fim de constatar o 
acerto ou o erro, o educador analisa o todo para observar o que já foi aprendido e o que ainda precisa ser edificado. A inclusão do ainda revela a concepção que entende a possibilidade de evolução permanente da aprendizagem dos alunos. Concepção que se manifesta, também, na prática do Professor C.

A primeira proposta lançada aos alunos da $6^{\mathrm{a}}$ série, no ano de 2005, foi a de discutirem quais as causas e conseqüências da movimentação da crosta terrestre. Por que temos os terremotos e vulcanismos em algumas regiões e outras apresentam essas atividades raramente? Como se encontra o Brasil em relação a essas atividades tectônicas? Esse assunto foi escolhido por dois fatores: a) porque fazia parte do objetivo planejado para ser estudado naquele período, que seria a estrutura geológica da Terra e a Teoria das Placas Tectônicas; b) recentemente, havia acontecido um grande tremor no fundo do Oceano Índico que provocara a formação de ondas gigantes que destruíram dezenas de cidades, matando milhares de pessoas no litoral de algumas ilhas asiáticas. Esse fenômeno ocorreu no final de dezembro de 2004 e foi amplamente divulgado pelos meios de comunicação, em razão das conseqüências geradas. Antes de levar os textos para casa, os alunos tiveram algumas aulas teóricas para compreenderem melhor o tema e, assim, poderem aprofundar a discussão em casa com os pais. O retorno dessa atividade superou as expectativas iniciais, tanto do professor como da equipe técnicopedagógica. No dia determinado para a discussão do tema em sala, quase todos os alunos estavam com os textos lidos e as anotações no caderno. No planejamento, o professor havia pensado que, no máximo, duas aulas fossem suficientes para a discussão. Em determinadas turmas, isso não foi possível, foram necessárias mais duas aulas para que todos pudessem tecer seus comentários. O mais interessante foi que nas questões subjetivas sempre havia alguma discordância entre os alunos e todos queriam dar as suas opiniões e a de seus pais, o que tornou o debate ainda mais rico. Em uma turma específica, uma aluna em especial chamou a atenção do professor. Ela possuía longas anotações em seu caderno e pedia para participar de todas as questões levantadas. As questões que o pai havia respondido juntamente com ela foram entregues repletas de argumentações, de elogios e sugestões para os próximos temas, sinal de que haviam realmente se debruçado sobre a proposta. Ao término das discussões em casa e em sala de aula, a etapa subseqüente foi uma prova escrita. "Ao corrigir as provas me deparei com uma situação inusitada: uma determinada página da prova, da referida aluna, estava completamente em branco, ou seja, ela não havia respondido nada e eram justamente as questões referentes ao tema das placas tectônicas. Não pude acreditar e cheguei à conclusão de que aquilo fora um descuido da aluna, pois as outras questões estavam todas respondidas e ela havia participado muito bem do debate. Escrevi um bilhete na página da prova para aluna dizendo que acreditava que aquilo teria sido um descuido dela e que ela precisaria, sempre 
que terminasse uma prova, uma atividade, uma produção de texto, fazer uma revisão minuciosa para ver se não havia esquecido nada e, muito menos, pulado alguma página, pois esse tipo de erro, em uma outra situação, poderia comprometer seriamente o resultado". Após conversarem, professor e aluna, sobre como resolveriam aquela situação, combinaram que o professor faria uma prova oral. "Pedi que respondesse oralmente as questões e pude confirmar que ela realmente sabia o que estava sendo solicitado. Além disso, elogiei-a pela participação e envolvimento em sala durante os debates e disse que naquele objetivo ela não teria problemas de resultado, mas se houvesse um objetivo relacionado à atenção e concentração, durante a realização da prova, ela ficaria para superação. Rimos os dois". (Professor C)

Tais posturas asseguram uma visão interacionista do processo educativo e uma dimensão diagnóstica/formativa/reguladora da ação avaliativa, uma vez que o professor considerou, desde o início do projeto, o conhecimento que os alunos já possuíam (ação diagnóstica), também refletiu a respeito de sua ação mediadora e o que ela poderia acrescentar aos saberes de sua aluna (ação formativa) e, ainda, detectou o erro e buscou uma outra forma do fazer pedagógico, a fim de ajustar o ensino e a aprendizagem (ação reguladora).

Desse modo, mais do que obter a resposta certa e manter-se inerte diante dos erros que podem acontecer, a ação pedagógica aproveita e transcorre por entre as possibilidades que se apregoam, buscando a todo tempo a compreensão das dificuldades do educando e a dinamização de novas oportunidades para a construção do conhecimento, a fim de esquadrinhar a superação do que ainda não foi consolidado. Prevaleceu um olhar compreensivo, não por ser tolerante e permissivo com as dificuldades, mas por ser reflexivo e interpretativo. O professor não negou o processo em decorrência do produto, mas questionou este em consideração àquele.

Os professores evidenciam, em seus discursos e práticas, que há no erro um "nó" que precisa ser desatado, conjuntamente, por eles e seus alunos, até porque reconhecem que uma avaliação formativa deveria possibilitar a "compreensão" da situação do aluno (Hadji, 2001b, p. 98) pelo professor e pelo próprio aluno.

Bem...O erro na avaliação formativa é diferente do erro na concepção tradicional. Na segunda, falando grosso modo, errou, você põe um " $E$ " na prova, no exame, no teste, como quiser chamar, e o problema é do aluno, pois eu professor digo: "já te ensinei, você que não aprendeu". Não há envolvimento do professor no processo, o professor é alguém neutro que ensina e ponto final. Agora, na avaliação formativa, o foco é outro, então, o erro faz parte do processo de aprendizagem. O erro precisa ser analisado em vários aspectos para se chegar a uma possível hipótese. Eu procuro 
trabalhar o erro de forma que o meu aluno não sinta vergonha ou medo, mas que ele entenda que há necessidade de um pouco mais para chegar lá. (Professor C)

Segundo o Professor C, se em um determinado período da história às vezes, ainda presente - o erro era considerado meramente um nãoacerto, hoje, em uma prática avaliativa compromissada com a edificação das aprendizagens, ele precisa tornar-se perceptível e inteligível para o professor e os alunos.

Superar o medo e a vergonha do erro constitui um primeiro passo que precisa ser seguido por outros: compreensão da natureza do erro, planejamento das ações de intervenção, proposição de tarefas diversificadas e significativas que abordem, sob outra roupagem, os mesmos aspectos de aprendizagem. Entretanto, essa não é uma tarefa simples, pois demanda um preparo e uma formação que os professores, de um modo geral, ainda não possuem.

Os saberes docentes precisam estar mais impregnados de informações sobre como os alunos aprendem, sobre as possibilidades e alternativas para a proposição de um mesmo conteúdo, sobre estratégias diversas para abordagem de uma mesma temática, sobre... Talvez por isso trabalhar com os erros discentes não seja um campo pacífico. As dificuldades são numerosas.

Para mim, os erros... demonstram o que meu aluno ainda não sabe, aquilo que eu preciso ensinar novamente... porém, esse ensinar novamente é muito mais complexo do que imaginamos, pois nem todos os erros cometidos pelos alunos podem ser considerados erros construtivos. Para o professor detectar os tipos de erros apresentados pelos alunos ele deve ter consciência de que, quando propõe estratégias de superação, precisa entender qual a função e a natureza dos erros, senão a intervenção não terá sucesso e nunca sairemos do velho discurso: "eu já tentei de tudo, mas esse aluno não aprende mesmo!", realmente já tentou de tudo, mas da maneira errada e aí a culpa continua sendo do aluno. (Professor D)

O chamamento para o ainda evidencia a preocupação do professor com as instabilidades inerentes a toda e qualquer travessia, com as distâncias existentes entre o aprendido e o planificado, entre o conquistado e o sonhado. Mas, ao mesmo tempo em que expressa inquietação, também revela confiança na possibilidade do vir a ser. Mas tudo dependerá da qualidade da intervenção, em decorrência da compreensão da natureza do erro.

Então, o docente precisa considerar os níveis de desenvolvimento em que seu aluno se encontra, ou seja, o nível real constituído pelo conjunto de conhecimentos já internalizados; e o proximal, ou potencial, constituído pelas funções ainda incompletas, representadas pelas 
atividades que o aluno só consegue realizar com a orientação de outra pessoa, ou uma ajuda ao processo de aprendizagem, ajuda esta que precisa ser mediada (Vygotsky, 1994).

Para compreender o erro manifesto e determinar sua tipologia, é interessante que o professor disponha de observáveis, o que corresponde à necessidade de construir um referido ou seja, o educador precisa estabelecer o ideal que deseja atingir com seus alunos, porém não pode deixar de lado [...] o que não é observável (Hadji, 2001b, p. 95). Para tanto, o professor necessita envolver-se, engajar-se na realidade de sua turma, dar relevância às relações que certos conteúdos da sua disciplina têm com outros componentes curriculares, ter visão de mundo e não apenas do "quadradinho da sua aula", ter a convicção de que formar é muito mais do que meramente treinar.

Assim, a preocupação do professor volta-se para a superação das aprendizagens, o que não constitui mero repetir quando o aluno demonstra incompreensão, mas em retomar o estudo em contextos diferenciados que considerem o erro enunciado. O professor necessita, então, de observar e interpretar as respostas de seus alunos, apropriando-se dos observáveis, porque pode determinar as presenças e ausências existentes na tarefa do aluno diante das metas estabelecidas. Cada resposta dos alunos revela possibilidades e limitações, diferentes quanto à dimensão e à intensidade, demandando variadas formas de intervenção por parte do professor. Por isso, é importante que ele faça uso de diversas maneiras de ensinar.

No decorrer de uma das aulas do Professor A, foi possível observálo, mais uma vez valendo-se de uma metodologia de trabalho que considera tais aspectos. Assim:

Durante o desenvolvimento do projeto de produção do CD - Universo em Jogo - os alunos passaram, primeiramente, pela etapa de pesquisa e produção do texto científico, tarefas executadas na sala de aula. Para darem continuidade à construção do $\mathrm{CD}$, propriamente dito, chegaram na fase de trabalho no laboratório de informática. Nesse momento, os textos já tinham sido elaborados, nos grupos. A equipe tecnológica da escola, juntamente com a professora do componente curricular, orientou os alunos sobre os procedimentos que deveriam ter em relação ao funcionamento do programa (programa que era específico para a produção do CD). Após as explicações, os alunos deveriam trabalhar com sua equipe. Os professores também disseram que estariam circulando pelos grupos e, quando precisassem de qualquer tipo de auxilio, era só chamá-los. Tudo parecia transcorrer de forma muito tranqüila; uma equipe ou outra tinha dúvidas. Enquanto os alunos trabalhavam, os professores circulavam pelos grupos e foram observando um tipo de erro "meio" diferente, pois não era de ortografia nem de concordância 
nominal ou verbal, mas de digitação. Após o término do trabalho, os professores conversaram sobre o que haviam constatado. Levaram ao conhecimento da assessoria psicopedagógica e, juntos, professores, equipe pedagógica e alunos, analisaram, refletiram, pesquisaram, debateram e chegaram a uma conclusão: que apesar de os educandos estarem "conectados" às tecnologias, como: Internet, MSN, e-mail e outras tantas, eles não sabiam datilografia, ou seja, o erro ali constatado era, basicamente, por nunca terem sido treinados a escrever usando as técnicas da datilografia. (Professor A)

Cabe ao professor, portanto, compreender as razões que ensejam os problemas de aprendizagem vivenciados pelo aluno, bem como levá-lo a vislumbrar suas próprias dificuldades, para que ambos possam trabalhar no sentido do avanço e da superação. Segundo Davis e Espósito, o professor precisa

[...] fazer com que os alunos tomem consciência dos erros cometidos, percebendo-os como problemas a serem enfrentados, sem que lhes imponham caminhos previamente traçados. Ora, se esta parece ser a proposta de ensino-aprendizagem derivada da teoria psicogenética, fica de imediato claro que, na avaliação do aproveitamento escolar, é tarefa docente a de discernir entre os erros construtivos isto é, aqueles que evidenciam progressos na atividade mental - e aqueles que não o são - isto é, aqueles que não sinalizam avanços na forma da criança pensar. (1990, p. 73)

Assim, as inquietações relatadas pelos Professores C e D são justamente as de que [...] erros de distintas naturezas estão sendo tratados de forma idêntica, quando exigem, para sua eventual superação, condutas pedagógicas diferenciadas (Davis, Espósito, 1990, p. 73).

Diferentes dificuldades exigem diversas formas de intervenção docente. Entretanto, os professores são formados para atuarem como se os alunos fossem todos iguais e aprendessem a mesma coisa, ao mesmo tempo e do mesmo modo. É preciso considerar as diferenças individuais na organização de atividades variadas que possibilitem a troca de informações e o confronto de soluções entre os pares. A tarefa de "corrigir" e "reorientar" os percursos de aprendizagem não precisa ser de responsabilidade direta do professor, mas pode ser uma missão compartilhada com os alunos.

O erro compreendido como parte do processo, sinalizador do movimento pelo qual o aluno vem construindo suas aprendizagens, requer do professor ações que propiciem re-direcionamentos e o aprofundamento desse processo. Destarte, haverá, necessariamente, a apresentação de novas situações desencadeadoras para a apropriação desses saberes. 
Essa perspectiva redimensiona a concepção de que a repetição das tarefas e atividades assegura a aprendizagem. Fazer novamente ou tornar a ensinar do mesmo jeito auxilia na memorização; no entanto, se a preocupação estiver em garantir a apropriação de um novo saber, a reprodução das informações muito pouco ajudará.

[...] O professor deve, desse ponto de vista, considerar-se como um instrumento de regulação, e ver nas variações de sua própria conduta (diferenciação de suas maneiras de ser e de fazer) um meio de ação que pode revelar-se particularmente eficaz. (Hadji, 2001a, p. 125)

O processo avaliativo deve assegurar a coleta de dados que informem sobre as aprendizagens edificadas, bem como sobre aquelas em curso. O processo, entretanto, não pode se restringir a isso. É preciso assegurar que as informações sejam transformadas em indicadores de superação, em balizas que orientem professores e alunos na proposição e consecução de desafios que assegurem a melhoria progressiva, a regulação do processo.

Quatro dos cinco professores investigados manifestaram esse entendimento quanto à função da avaliação e ao tratamento do erro.

A gente precisa entender os tipos de erro e daí agir em cima deles. E isso não é fácil. Às vezes usamos o antibiótico menos apropriado para combater uma enfermidade, não é? O mesmo acontece na nossa ação pedagógica, usamos estratégias didáticas totalmente ineficientes para determinados erros. À medida que você vai conhecendo seus alunos e suas dificuldades é importante ir selecionando atividades, desafios, tarefas e mediações diversificadas que possam, na medida do possivel, atender às diferentes necessidades. (Professor C)

Se eu ensinei do jeito $A$ e eles não entenderam, não adianta continuar ensinando do mesmo jeito, eu vou precisar encontrar um jeito $B, C, D, E$... para que aquele aluno ou aqueles alunos se apropriem de uma nova aprendizagem. (Professor B)

Às vezes eu preciso dizer: espera aí, vamos lá, vamos retomar nosso raciocínio, vamos parar, pensar, analisar, e isso pode ser com uma aula expositiva, com um trabalho em grupo, com uma tarefa mais especifica. (Professor A)

Eu procuro usar o erro como uma estratégia didática, trabalho com possibilidades; assim, levantamos hipóteses a partir de suas próprias descobertas. Algumas vezes, essa estratégia não atinge o que eu esperava, os alunos vão além, trazendo conhecimentos relevantes e motivadores. (Professor D)

Os problemas expressos pelos professores em adequarem as tarefas às dificuldades de aprendizagem remetem para um cenário de onde emergem novas reflexões.

É importante destacar a presença implícita de um conceito de erro enquanto indicador diagnóstico, até porque a análise dos resultados 
obtidos nos diversos instrumentos gera diferentes repercussões, que se traduzem em variabilidade didática no interior da sala de aula.

A compreensão da importância do erro para o aperfeiçoamento do processo didático não assegura ao professor os meios para superá-lo. É necessário também compreender a sua natureza, determinar a sua tipologia, para que a intervenção ocorra da maneira mais adequada e no momento mais oportuno. Ainda, é preciso dispor de um "arsenal" de técnicas que lhe possibilitem alternativas para a re-apresentação do assunto.

No entanto, os professores parecem ter dificuldade - em alguns momentos - para diversificar as atividades de ensino. Preocupam-se em explicar de um outro modo, em falar de um outro jeito, revelando uma ambigüidade muito presente: a incerteza quanto ao potencial de enfrentamento de um desafio e a certeza advinda da explanação detalhada de um determinado conteúdo.

Para adequar a atividade ao tipo e ao nível da dificuldade revelada pelos erros, é importante reconhecer que eles podem ser de variadas naturezas, sugerindo diferentes interpretações (Carvalho, 1997). Por isso, o professor necessita saber que funções cognitivas ele quer enfatizar quando propõe determinadas questões e, ainda, criar condições pedagógicas diferenciadas para trabalhar cada uma delas. Se a ênfase se situa na capacidade que o aluno tem para reter de informações (dados e fatos) de determinado conteúdo, as atividades propostas exigirão memorização e reprodução; se, por outro lado, a ênfase se situa no quanto o aluno é capaz de sintetizar, analisar, elaborar, obviamente as atividades apresentadas serão outras, e para cada tipo de dificuldade ou insuficiência de aprendizagem identificadas, deverão ser reservados momentos e estratégias para a retomada do processo de ensino.

É relevante dizer que, para os professores estudados, aprender não se resume à capacidade de repetir o que foi ensinado, tampouco se limita à aptidão em reproduzir o modelo proposto sem nenhuma reflexão, mas significa revelar de forma ativa, participativa, individual ou coletiva as inconcretudes do processo empreendido até então.

Para asseverar as palavras, as práticas desenvolvidas por esses professores evidenciam sua percepção de aprendizagem - e do papel do erro em seu decurso.

Após uma atividade, sem consulta, cujo objetivo era de sondar se os alunos haviam compreendido os diversos fatores que interferem nas variações climáticas, um determinado aluno, inverteu os hemisférios e esqueceu ou confundiu que, quando na Europa é verão, aqui no Brasil é inverno. 
Analisando essa situação o professor ponderou que, mesmo invertendo os hemisférios, o aluno descreveu corretamente em cada um deles o clima, a vegetação, as dinâmicas atmosféricas, que as regiões próximas à Linha do Equador, via de regra, são mais quentes do que as regiões mais afastadas e, ainda, teve uma excelente argumentação e coerência nas proposições levantadas. O professor também ponderou sobre a participação do aluno em sala, suas tarefas e seu caderno de anotações e decidiu, na correção, considerar a questão correta. Todavia, escreveu no final da prova: "Aluno A, você teve uma excelente argumentação e coerência na resolução de sua atividade, porém, tenha mais cuidado na hora de responder, pense um pouco mais e releia sua resposta para ver se não trocou nada, não esqueceu alguma coisa, pois na questão número 06, você trocou os hemisférios". "Por favor, venha falar comigo". Assim, após a devolução da atividade, o professor reuniu os alunos em pares e pediu que discutissem a correção, e se tivessem alguma dúvida ou discordassem da correção era só falar com ele. Depois de algum tempo, o aluno A, veio até o professor e disse: "Professor, acho que eu não merecia ter essa questão como certa". "Por quê?, pergunta o professor." "Ah! Porque eu errei, não respondi a questão totalmente certa". "É verdade!", diz o professor, mas se eu te perguntasse agora: o hemisfério sul fica abaixo ou acima da Linha do Equador? O Brasil fica no hemisfério sul ou norte? E a Europa? O que você me responderia?" "É claro que fica abaixo, o Brasil fica no hemisfério sul e a Europa no hemisfério norte" diz o aluno. "Então, por que eu deveria ter considerado sua resposta errada, pois eu entendi que a essência do conteúdo você havia compreendido e até mesmo extrapolado seus conhecimentos para o nosso dia-a-dia, só que havia trocado os nomes dos hemisférios, mas como você acaba de me mostrar, você sabe muito bem onde ficam os hemisférios sul e norte, ok?" "É, eu sei mesmo, e agora entendi que sempre devo fazer uma segunda leitura daquilo que escrevi, porque posso errar, mesmo sabendo." "É isso aí, cara!" Diz o professor. (Professor C)

Nota-se, pela observação da correção de um instrumento de avaliação, que houve preocupação em considerar as hipóteses levantadas pelo aluno e tratá-las com seriedade. O problema ou dificuldade em trocar os hemisférios foi percebido pelo professor, porém tornou-se fonte de reflexão que direcionava a organização do pensamento com uma correção formativa e não coercitiva; o professor assegurou a possibilidade de o aluno superar o problema, evidenciado na situação analisada.

Segundo o Professor D, o aluno, sem as limitações decorrentes da obrigação de acertar sempre, pode revelar suas idéias sobre um fenômeno ou fato, confrontando-as e superando as dificuldades encontradas. Então, considerar e compreender os movimentos do aluno em direção à elaboração, à síntese e à apropriação do conhecimento são fatores que favorecem o processo de 
construção dos saberes, principalmente quando este é "obstruído" por dificuldades das mais variadas naturezas.

Já a desconsideração ou não-compreensão da atividade ou ação desenvolvida pelo educando e a correção, no sentido de reprodução de um modelo único e absoluto, podem interromper todo um processo, pois quando a intervenção pedagógica se resume a corrigir e transmitir, é inevitável a limitação na reformulação de hipóteses, na re-significação de conceitos, na articulação de novos saberes, de tal modo que o professor, muitas vezes, precisa [...] aproximar-se da lógica do aluno e compreendê-la (Esteban, 2002, p. 139) para só então transformar sua análise a respeito o erro.

\section{TECENDO CONSIDERAÇÕES}

Aceitar o erro como elemento do processo de construção do conhecimento não significa ignorá-lo, aguardando que o aluno o perceba sozinho, ou, então, considerá-lo e induzir o aluno à resposta correta. Fonte de informações, o erro precisa ser entendido, balizado e superado, por meio de [...] métodos, técnicas e procedimentos de ensino (Davis, Espósito, 1990, p. 74). Assim, é função do professor possibilitar que o erro se torne "observável" (Hadji, 2001a) para que possa (re)formular seus procedimentos de ensino, a fim de que todos os seus alunos alcancem os objetivos propostos para aquela etapa de escolaridade.

Dos cinco professores observados, quatro - A, B, C e D reconhecem a relevância do estabelecimento de padrões ideais a serem atingidos pelos educandos, embora demonstrem apreensão de que a avaliação não deve se restringir a considerar os resultados, os escores obtidos. Desse modo, a não-observância, pelo professor, dos conteúdos conceituais, procedimentais e atitudinais, impossibilita a percepção e a valorização das aprendizagens significativas e as realizações dos alunos.

Por isso, extrapolar a concepção de avaliação, que limita a significação do erro a termos literais, é condição básica para desencadear metodologias de investigação e análise que impliquem transformar práticas inflexíveis em possibilidades de crescimento do processo de ensino/aprendizagem, garantindo, assim, indivíduos estruturados e, portanto, mais confiantes e com mais autonomia, em razão do domínio que têm de si mesmos sobre a real apropriação de seus saberes e de suas limitações. 


\section{REFERÊNCIAS BIBLIOGRÁFICAS}

BLOOM, Bejamin S.; HASTINGS, J. Thomas; MADAUS, George F. Manual de avaliação formativa e somativa do aprendizado escolar. São Paulo: Pioneira, 1983.

CARVALHO, José Sérgio Fonseca de. As Noções de erro e fracasso no contexto escolar: algumas considerações preliminares. In: AQUINO, Julio Groppa (org.) Erro e fracasso na escola: alternativas teóricas e práticas. São Paulo: Summus, 1997.

DAVIS, Cláudia; ESPÓSITO, Yara Lúcia. Papel e função do erro na avaliação escolar. Temas em Debate. Cadernos de Pesquisa. São Paulo: Fundação Carlos Chagas, n. 74, p. 71-75, ago. 1990.

ESTEBAN, Maria Teresa (org). Avaliação: uma prática em busca de novos sentidos. Rio de Janeiro: DP\&A, 1999.

O Que sabe quem erra? Reflexões sobre avaliação e fracasso escolar. 3.ed. Rio de Janeiro: DP\&A, 2002.

FOUCAULT, Michel. Vigiar e punir: nascimento da prisão. Tradução: Raquel Ramalhete. 30.ed. Petrópolis, RJ: Vozes, 2005.

HADJI, C. A Avaliação desmistificada. Tradução: Patrícia C. Ramos. Porto Alegre: Artmed, 2001a.

Pensar e agir a educação: da inteligência do desenvolvimento ao desenvolvimento da inteligência. Porto Alegre: Artmed, 2001b.

HOFFMANN, Jussara. Pontos e contrapontos: do pensar ao agir em avaliação. 7.ed. Porto Alegre: Mediação, 2002.

LA TAILLE, Yves de. O Erro na perspectiva piagetiana. In: AQUINO, Julio Groppa (org.) Erro e fracasso na escola: alternativas teóricas e práticas. São Paulo: Summus, 1997.

LIBÂNEO, José Carlos. Tendências pedagógicas na prática escolar. ANDE, São Paulo, n. 6, p. 11-23, 1983.

LUCKESI, C. C. Avaliação da aprendizagem escolar. 14.ed. São Paulo: Cortez, 2002. 
OLIVEIRA, A. Benê de; TESCAROLO, Ricardo. Avaliação formativa: por quê? Boletim Informativo. Londrina: Colégio Marista de Londrina, s.d.

PERRENOUD, Philippe. Avaliação: da excelência à regulação das aprendizagens. Porto Alegre: Artmed, 1999.

RABELO, Edmar Henrique. Avaliação: novos tempos, novas práticas. Petrópolis, RJ: Vozes, 1995.

SAVIANI, Demerval. Da nova $L D B$ ao novo plano nacional de educação: por uma política educacional. 4.ed. rev. Campinas: Autores Associados, 2002. (Coleção Educação Contemporânea).

SOUZA, N. A. Sol e sombra: a relação teoria-prática na formação do professor. In: ALVARENGA, G. M. (org). Avaliação: o saber na transformação do fazer. Londrina, PR: Núcleo de Estudos e Pesquisas em Avaliação Educacional, 2002.

VYGOTSKY, Lev Semenovich. A formação social da mente. São Paulo: Martins Fontes, 1994.

Recebido em: junho 2006

Aprovado para publicação em: setembro 2006 